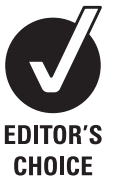

CHOICE
- Additional appendices are published online only. To view these files please visit the journal online (http://pmj.bmj. com)

Allergy \& Respiratory Research Group, School of Community Health Sciences: General Practice Section, University of Edinburgh, Edinburgh EH8 9DX, UK

\section{Correspondence to Dr C Burton, Allergy \& Respiratory Research Group, School of Community Health Sciences: General Practice Section, University of Edinburgh, 20 West Richmond Street, Edinburgh EH8 9DX, UK; chris.burton@ed.ac.uk}

Sponsors: The study was jointly sponsored by The University of Edinburgh and NHS Lothian. The sponsors had no involvement in the conduct or reporting of the study.

Received 11 October 2009 Accepted 12 December 2009 Published Online First 10 August 2010

\title{
Understanding the experiences of allergy testing: a qualitative study of people with perceived serious allergic disorders
}

\author{
Christopher Burton, Tasneem Irshad, Aziz Sheikh
}

\section{ABSTRACT}

Purpose To investigate the experience of patients with perceived severe allergic disorders in obtaining allergen testing.

Design In-depth interviews with 20 purposively sampled adults and parents of children with, or at perceived risk of, serious allergic problems. Data were analysed thematically, drawing on Frank's classification of narratives to help interpret patient/carer accounts. Results Accounts fell into four main groups: (i) children with anaphylaxis occurring 'out of the blue' (ii) children in whom the recognition of severe allergy by professionals was perceived as delayed; (iii) adults with anaphylaxis who adapted; and (iv) adults who remained in search of an answer. Whereas children had eventually been assessed and tested in a specialist clinic, adults had difficulty in obtaining testing, and most-including those for whom current guidelines would recommend testing - had not been tested. Participants incorporated their past experience of testing into narrative accounts, which included current ways of dealing with their allergy. They saw testing as only one component of appropriate allergy management which required interpretive expertise in professionals who ordered tests. Despite the limitations in NHS allergy testing provision, there was relatively little interest among patients/carers in using complementary and alternative providers of allergy testing.

Conclusions Patients perceived major shortfalls in relation to NHS allergy testing provision, focusing on both the availability of testing and expertise in interpreting the results. Any increased provision of testing needs to be matched by access to specialist interpretation of these tests.

\section{INTRODUCTION}

Serious and life-threatening allergic disorders such as anaphylaxis are increasing in incidence. ${ }^{1-3}$ As these conditions are triggered by contact with allergens, patients at risk of further reactions need to know which substances to avoid. Testing for sensitivity to specific allergens is explicitly recommended in national ${ }^{4}$ and international ${ }^{5}$ guidelines for the management of anaphylaxis.

The UK has an underprovision of allergy specialists, ${ }^{67}$ and there is evidence that many patients for whom allergy testing is indicated do not receive it. ${ }^{8}$ In the absence of any major expansion in specialist allergy services, some authors have advocated promoting testing in primary care. ${ }^{9}$ This vacuum in NHS provision has allowed a proliferation of routes through which patients can now obtain various forms of allergy testing, including high street pharmacies ${ }^{10}{ }^{11}$ complementary and alternative health practitioners, ${ }^{12}$ and mail order. ${ }^{13}$ The concern is, however, that these tests may be carried out by practitioners with limited expertise, sometimes using discredited methods, ${ }^{14}$ and carry the potential for incorrect diagnosis and inappropriate advice.

In order to understand patients' perspectives, we carried out a qualitative interview study of the experience of obtaining allergy testing. We chose this approach, as qualitative research methods allow an in-depth appreciation of patients' motivations and experiences. ${ }^{15}$

\section{METHODS}

We purposively recruited participants (adults and parents of young children, of both genders) who had, or perceived themselves to have, serious allergies in Lothian in 2008. Ethical and governance approval were obtained from Lothian Local Research Ethics Committee and Lothian Health Board.

\section{Sampling}

We recruited participants from three primary sources: general practices; a newly developed specialist paediatric allergy clinic; and the Anaphylaxis Campaign (a patient support and advocacy organisation). These approaches were supplemented by snowball sampling in order to help identify under-represented groups. Potential participants were identified from primary care by searching for those with an allergy-related Read code (appendix 1 online) and/or prescription for self-administered epinephrine; these participants were then sent written invitations to participate from their general practitioners (GPs). Specialists in the paediatric allergy clinic invited patients attending clinics both by letter and personal invitation. The Anaphylaxis Campaign emailed their local membership with details of the study.

The initial invitation included a short questionnaire designed to enable us to select a maximum variation sample. Responding individuals were followed up by telephone to answer any further questions and, where appropriate, to set a time for an interview. Written informed consent was obtained before interview.

\section{Interviews}

Participants were interviewed at a time, place (usually at home) and language of their choosing. Interviews followed a topic guide (appendix 2 online), which evolved throughout the study and were audiorecorded, translated where necessary, and transcribed. Field notes were used to aid contextualisation of data. We continued to 
interview until we achieved saturation on key themes, such as pathways to testing for children and participants' views about clinicians' roles in allergy testing.

\section{Analysis}

We analysed interview transcripts throughout the period of data collection to allow emerging themes to be fed back into subsequent interviews. Constant comparison ensured that the thematic analysis approach used represented all perspectives, and we actively sought examples of opposing views and deviant cases. ${ }^{16}$ As it became apparent that consistent narrative patterns were emerging, we sought to consider these in relation to prior models and theories of illness understanding. Specifically, we chose Frank's classification of narratives, which has been found to be useful in a range of clinical settings. This categorises patients' narratives into three types: restitution, quest or chaotic. ${ }^{17}$ Restitution narratives are the default illness story: 'I became unwell, I went for treatment, I got better'. Quest narratives describe a response to illness in which treatment does not lead to restitution, but instead results in an alternative but nonetheless still valued outcome: perhaps successful adaptation or a new view of oneself. Finally, chaotic narratives seem to have no purpose or direction, with no end in sight; they are lived, by the individual, rather than observed and understood by others. Data were analysed with the aid of NVivo 7.

\section{RESULTS}

We initially approached a total of 94 patients/parents (60 through seven GP practices; 19 through the paediatric allergy clinic; and 15 via the Anaphylaxis Campaign). Thirty-one individuals responded, from whom we selected a purposive sample of 20 participants, of whom seven were parents of children diagnosed as having (or at high risk of) anaphylaxis and 13 were adults, six of whom had a history of anaphylaxis while the remainder had a range of allergic and possibly allergic conditions (table 1). Despite our attempts to obtain a broad sociodemographic spread, all but one participant was of white British origin, and most had professional or skilled occupational backgrounds.

All the children in our study were allergic to one or more foodstuffs and had received specific allergen testing through the paediatric allergy clinic, usually after a first episode of anaphylaxis. Only two of the six adults with a history of anaphylaxis had been tested, one $>20$ years earlier and the other recently after arranging a private consultation outside of the NHS. None of the other adults had been allergy tested.

During the study it became clear that there were four distinct patterns being described by participants: (i) children with anaphylaxis occurring 'out of the blue'; (ii) children in whom the recognition of severe allergy was perceived as delayed; (iii) adults with anaphylaxis who adapted; and (iv) adults in search of an answer. We consider each trajectory in turn.

\section{Children with anaphylaxis out of the blue}

These children who had suddenly become seriously unwell, without warning, were tested as part of their initial evaluation either while in hospital or shortly afterwards. In most, but not all cases, the trigger was apparent to the parent.

Table 1 Characteristics of participants

\begin{tabular}{|c|c|c|c|c|c|c|}
\hline ID & Group* & Recruitment source & Sex & Allergic diagnoses & Self-reported allergens $\dagger$ & Test history $\ddagger$ \\
\hline 01 & $A$ & Paediatric allergy clinic & M & Anaphylaxis from age 5 & Latex, nuts, egg, prawn & SPT \& RAST \\
\hline 02 & B & Paediatric allergy clinic & M & $\begin{array}{l}\text { Allergic vomiting as infant, urticaria, } \\
\text { asthma; at risk of anaphylaxis }\end{array}$ & $\begin{array}{l}\text { Wheat, egg, nuts, peas, lentils, banana, } \\
\text { kiwi, fish, cat hair, dust mite }\end{array}$ & SPT \& RAST \\
\hline 04 & B & Paediatric allergy clinic & M & $\begin{array}{l}\text { Anaphylaxis before } 1 \text { st birthday preceded } \\
\text { by allergic vomiting when weaning, }\end{array}$ & $\begin{array}{l}\text { Dairy, egg, wheat, sesame seeds, most } \\
\text { nuts }\end{array}$ & SPT \& RAST \\
\hline 06 & A & Paediatric allergy clinic & M & Anaphylaxis at age 2 & Nut & SPT \& RAST awaiting nut challenge \\
\hline 08 & D & GP & $\mathrm{F}$ & $\begin{array}{l}\text { Marked local reaction to bee stings, no } \\
\text { anaphylaxis }\end{array}$ & Bee stings & None \\
\hline 09 & D & GP & $\mathrm{F}$ & $\begin{array}{l}\text { Chronic idiopathic urticaria, no } \\
\text { anaphylaxis }\end{array}$ & Urticaria, hay fever & None \\
\hline 10 & D & GP & $\mathrm{F}$ & $\begin{array}{l}\text { Asthma, urticaria, no anaphylaxis (but } \\
\text { grandson with anaphylaxis) }\end{array}$ & $\begin{array}{l}\text { Pollen, dogs, cats, hay, grass, sprays, } \\
\text { dust, soaps }\end{array}$ & None \\
\hline 14 & A & Anaphylaxis Campaign & M & $\begin{array}{l}\text { Anaphylaxis to peanuts, cold-induced } \\
\text { urticaria }\end{array}$ & Peanut, cold climate & SPT \& RAST \\
\hline 16 & C & GP & $\mathrm{F}$ & Anaphylaxis onset young adult & Pollens, shellfish and kiwi & None \\
\hline 17 & C & GP & $\mathrm{F}$ & Anaphylaxis from age 7 & All nuts and nut products & None \\
\hline 21 & D & GP & $\mathrm{F}$ & Asthma, eczema, no anaphylaxis & Multiple food, pollen, etc & Patch \& Vega \\
\hline 22 & C & GP & M & Anaphylaxis to wasp sting aged 40 & Grass pollen, wasp venom & SPT \& RAST \\
\hline 23 & C & GP & $\mathrm{F}$ & Anaphylaxis at age 19 & Dry roasted peanut, Californian wine & SPT \\
\hline 25 & B & Paediatric allergy clinic & $\mathrm{F}$ & $\begin{array}{l}\text { Anaphylaxis as toddler, preceded by bad } \\
\text { eczema when weaning }\end{array}$ & Nuts, egg & RAST \\
\hline 28 & C & Snowballing & M & Anaphylaxis & Nuts & Patch \\
\hline 29 & D & Snowballing & $\mathrm{F}$ & Oral allergy syndrome & Walnut, dried date, apricot & None \\
\hline
\end{tabular}

${ }^{*} \mathrm{~A}$, children with anaphylaxis occurring 'out of the blue'; $B$, children in whom the recognition of severe allergy was perceived as delayed; $C$, adults with anaphylaxis who adapted; $D$, adults in search of an answer.

†Patient's self-report of nuts commonly included peanuts (strictly legumes); we did not attempt to differentiate these from true nuts.

$\ddagger$ Patch, skin patch testing; RAST, radioallergosorbent testing for lgE in blood; SPT, skin prick test; Vega, VegaTest, a form of electrodermal testing 
'He ate a brazil nut and then had a very acute severe abdominal pain and was then sick and went bright red and very wheezy and was struggling to breathe. So we went up to A\&E and he was given adrenaline and nebuliser and things and settled down....he had the RAST [blood] test in the hospital before his outpatient appointment, that said he only showed positive to brazils.'

(Participant 06, child with anaphylaxis to food)

The narrative style of this group of interviewees was typically of a restitution type ${ }^{17}$ : anaphylaxis represented a problem and the parents and professionals solved it. Typically in this group, testing was seen as part of the routine process of care. Test results were seen as predictable and in keeping with the patients' and clinicians' understanding of the condition-a narrative feature indicating the individual's ability to control the threat of illness. ${ }^{17}$

'So we went to hospital and they did skin tests and he said, 'We don't really need to do this because it's quite obvious what he's allergic to but we need to do it just to clarify things' so that they just did, um the skin test then and they said, 'Yes he's really, really high'. The reading was-I can't remember how it was but you know, they said if it was much higher it would be off the Richter Scale sort of thing because it was very high, and just to make sure that he avoids all nuts but especially peanuts.'

(Participant 14, parent of child with anaphylaxis to food)

\section{Children in whom the recognition of severe allergy was perceived as delayed}

Before their first episode of anaphylaxis, these children had other symptoms which, with hindsight, were indicators of severe food allergy. Three had marked vomiting, either with formula milk or after weaning, and the fourth had been referred to a dermatologist for severe eczema. These accounts were characterised by reports of parental concern being dismissed or obstructed by professionals, in some cases leading to frustration and anger. Primary care practitioners (GPs and health visitors in particular) were seen as out of their depth in failing to recognise problems promptly.

'I was convinced, I was convinced that the milk was the problem for him [son] and that came up, I mentioned the possibility although we have got no family history of milk intolerance, I mentioned that numerous times [to the GP] but was told it was very unlikely.'

\section{(Participant 03, parent of child with anaphylaxis to food)}

Two of the children with eczema were tested for allergy to milk, eggs and nuts, although it appears that the possibility of anaphylaxis was not raised with the parents after testing. Thus when anaphylaxis did happen, it was unexpected:

\begin{abstract}
'...when I was going back to work I put him onto soya formula instead of normal formula, but he started reacting to that and bringing up every feed and his skin was really bad ... so we got into the process of: oh yes we will need blood tests taken, and it came back oh yes he is allergic to: dairy, wheat, eggs, soya and nuts as well, so we said this to the nursery where he was ... and unfortunately he grabbed something off somebody else's high chair-toast with butter, so wheat and dairy. So I got a phone call; I didn't realise it was an anaphylactic reaction.'
\end{abstract}

(Participant 04, parent of child with anaphylaxis to food)

Although we had focused on testing, it became apparent from parents' accounts that it was the recognition of severity that they felt was missing. In contrast with the predictable tests of the first group, tests were described in neutral or even perplexing ways:

'And so yes [when the parents got the results] because such a long time had passed, you know, [the GP said] that her skin is better, it doesn't look as though her skin's affected by food....but I do have this piece of paper that says she has an allergy to nuts and eggs.'

(Participant 25, parent of child with anaphylaxis to food)

'To wheat he is very allergic, milk was the funny one because I think whenever it came back he was always almost borderline, just over but almost borderline but yet his sensitivity is quite high, I mean his reaction to things so when he comes into connection with milk he reacts quite badly even despite the levels being relatively low in comparison to his other allergies.'

(Participant 03, parent of child with anaphylaxis to food)

Although participants ultimately described the interpretation of tests by a specialist as a useful source of information, the tests themselves were uncommunicative:

'I remember the girl that gave us our results wasn't that helpful, she was saying, 'Oh yes' and giving us all the numbers and everything, oh he is $200 \ldots$ IU for this and that... but that doesn't mean anything to us and it is only since then and we have had discussions with other consultants and things that we actually know more about it and in comparison, because 200 compared to what? You know, and the overall IU was over 2000-is that good or bad? Obviously now we know it is really bad.'

(Participant 04, parent of child with anaphylaxis to food)

These narratives described a quest for diagnosis and recognition $^{17}$ : a telling of the story to communicate the individual's response to difficulty and the control they obtained through finding a solution. However, the testing was not the end of the quest-rather the search was for information, or confirmation, by a specialist.

\section{Adults with anaphylaxis}

This group varied in their experiences of obtaining testing, but most had found it very difficult to get allergy tests through the NHS. Some had been unable to obtain testing at all; others had been tested privately or chosen to manage without testing as it was apparently unavailable. In contrast with the parents of allergic children with delayed diagnosis, these patients generally perceived their GPs as supportive, but unable to help because they had no specialist service to refer patients to:

'....so it was a while back and um, but I asked about allergy testing then and he said, 'we don't do that'. And then this last time, it happened in September when I went and had the problem with mustard and again I came back... so now that I know that I'm really allergic to mustard I think I really should be carrying an EpiPen and he's like, 'Yes you should' and he actually looked into allergy testing and I contacted the University Health...

Occupational health people about allergy testing as well because I was having problems with work... and as far as I'm aware you can't get allergy testing in Edinburgh! I mean sort of well I've been led to believe.'

(Participant 16, adult with anaphylaxis to food)

In one somewhat atypical case, the GP appeared able and willing to deal with testing, and there was no perceived need for specialist testing or interpretation; however, the patient had a clear history of anaphylaxis after a wasp sting and testing was carried out to exclude other allergies. 
'So I went to see the doctor and so he said, he said, 'Right well we'll carry out some tests' and so he did all the various ones for like blood and $u m . .$. he took blood samples, you know, into vials.... basically said that he would send them, all away to be tested at the university or something, for you know, wheat, pollen, you know what else, bread um...etc, whatever a whole range of tests and I may have a note about it somewhere .... [then he] phoned me and I went back to see him and he said, 'They've all come back clear.'

(Participant 22, adult anaphylaxis to venom)

Some adults did not seek testing because they did not think this would add anything to what they now knew:

\begin{abstract}
'...because I don't think there's anything to be gained. You know, I know what I'm allergic to, I know my response, I know what to look out for and I have an EpiPen and beyond that... Well, if I went for a test it would tell me I was allergic to nuts. And I know that, so... I don't think there would be any point really.'
\end{abstract}

(Participant 17, adult with anaphylaxis to food)

This group of interviewees also recounted predominantly quest narratives; however, for many the end result of the quest was not a medical diagnosis, but self-knowledge. Here the quests contained what Frank describes as contingency ${ }^{17}$ in which one surrenders a form of control over uncertainty (in this case medical knowledge) in exchange for a deeper truth (personal experience). These accounts typically included a perceived need for testing in the past, which the individual overcame by depending on their own experiences as a guide. As a result, in these accounts, patients balanced the unavailability of the tests by emphasising the limitations of testing.

\section{Adults at low risk who sought testing}

This group of interviewees reported a range of medical conditions, some clearly in the allergic spectrum, others less so. None had been tested through the NHS, but all felt they should have been. Participants expressed a range of opinions about why testing was not available for them.

Some perceived the lack of testing as a judgement by their GP which, while framed as rational on the part of the GP, did not make sense to the patient

'Initially, you know, the first thing, you know, he actually just said, 'Keep having it [antihistamine]', but after a while he said, 'Just to have it when you feel you need it' and I said, 'Well what am I allergic to?' and he said, 'I have given up (finding) about what people are allergic to... because it disappears as quickly as it comes' and that was six years ago... I just said, 'Do I not get tested to find out what it is' and he said, 'No, it's not worth it.'

(Participant 09, adult with idiopathic urticaria)

\section{Others saw this as a bias in the healthcare system which was understandable, but unfair.}

'I think there's been a lot of stuff in the press that is making it sound as if everybody's saying they've got allergies and they don't, and so GPs are thinking, 'I can't be bothered with them' just, you know, 'Give them some Piriton if it shuts them up', but not really looking into do they actually have an allergy and is it actually a serious allergy? Do you know that they should be doing something about it they should be looking at it?'

(Participant 10, adult with asthma and urticaria)

These accounts tended to have a chaotic pattern: there was no clear narrative trajectory and often the account jumped from the individual to relatives with allergy and their experience without clear direction. ${ }^{17}$ In contrast with the adults with anaphylaxis who sought testing but found ways of dealing with its nonavailability, this group sought to apply more of the same pressure or to try alternative routes to testing such as through complementary and alternative providers. However, whatever they tried appeared to result in dissatisfaction and a feeling that no end had been met.

\section{Patients' views of the role of testing}

An overarching theme was that, in most cases where testing had been carried out, patients, or their parents, depended on the interpretation of these results by specialists. In particular, patients sought help to integrate the objective test results with their subjective experiences in making sense of allergy and looked for expert advice in using tests to plan subsequent controlled exposure.

'... we have had a couple of inadvertent exposures to nuts in the last year or two because he is more independent of his diet now-it has been OK and I think that has created the uncertainty and that is why I felt now is the time to push for further testing because if he becomes confident, if he thinks he is not allergic and inadvertently has a certain nut and he is OK with it, then he might start to take risks with it so I think it is now that seems the right time to re-visit the whole allergy thing because he has been absolutely fine with it, we have had no hint of an allergy since aged two.'

(Participant 06, parent of child with anaphylaxis)

In several cases, individuals demonstrated complex and balanced reasoning around tests and their limitations such that they would only have further testing if they thought it could give clear answers.

'Well the only tests I'm aware of are the skin prick tests which don't really seem to mean that much. Yes, the pollen thing had a bit of an effect but I don't know of any tests that would be of any use. I've heard of these blood tests but I've also heard that they're not particularly conclusive and, you know,...saying that, you know, they tell you that you're allergic to things that you're not and then they don't pick up on things that you are so I'm not convinced that they're worth doing or I would. But I feel I'm beginning to know myself, I have to avoid certain things, but it doesn't affect my life too much, you know I just avoid peanuts and tomatoes.'

(Participant 23, adult with anaphylaxis to food)

This prior consideration of the implications of test results was in marked contrast with several of those not tested who appeared to have a more straightforward view of the value of testing:

'I would like him to actually, you know, either do the blood test himself or if he couldn't, refer me somewhere that would actually do it and say, actually I think I'd actually like the skin prick thing and the blood test, and then at least I would know for definite instead of it driving you absolutely crazy when you have a really bad day and you're sort of what did I eat yesterday, what did I eat, did I touch.'

(Participant 20, adult with asthma and eczema)

Overall it was clear that respondents who had had tests saw the testing not in isolation, but as part of a broader package of care that required expert interpretation.

'I don't think the [GP] would have the specialist knowledge to do that really-I think that would just be an extra for them to ... what 
I quite like about going there [specialist clinic] is the expertise or certainly the perceived expertise from my point of view because I think it is a bit of a specialist subject really.'

(Participant 06, child with anaphylaxis to food)

\section{Role of complementary and alternative allergy testing}

We expected that, given the limitations described in NHS provision of allergy testing, several of our participants would have sought testing from alternative providers, but this was not the case. Instead complementary medicine was seen as a valued option for dealing with manifestations of allergy (for instance, skin creams) or dealing with stress which might trigger allergy (acupuncture). Only one parent of an anaphylactic child had used non-conventional testing, and even then only in a confirmatory way. In contrast, although only one of the non-tested non-anaphylactic group had used alternative testing, most were willing to consider it. We found no suggestion that complementary medicine overtook the use of conventional medication: in particular, there was no indication that self-administered epinephrine use would be compromised in the event of an emergency.

\section{DISCUSSION}

\section{Summary of main findings}

Adults and some parents of children with, or at risk of, serious allergy described real difficulty obtaining allergy testing. This problem persists despite being repeatedly highlighted by patients and carers, professional groups and parliamentary reviews. We found that accounts of illness and diagnosis, which included testing (or not) featured characteristic narrative approaches and that these approaches appeared to reduce the threat of both the allergy itself and the perceived lack of adequate health service provision. Of particular note is that all participants with anaphylaxis saw testing as only one part of a broader package of expert care.

\section{Strengths and limitations of the study}

This is, as far as we are aware, the first in-depth interview study of patients'/carers' accounts of allergy testing in a clinical population diverse in age and clinical conditions. We purposively sampled participants, including adults and the parents of children, from a variety of sources. While the study was limited to one urban area of Scotland, we aimed to make it generalisable within the UK by recruiting patients from medical practices serving socioeconomically deprived districts and minority ethnic groups, although this proved difficult. By recruiting from a recently redeveloped paediatric allergy clinic, we may have identified a particularly appreciative group of parents; however, their stories of severe difficulties in obtaining testing before the current improvements point to problems that are likely to occur elsewhere. Although a few areas of the UK have well-established specialist allergy services, the majority are either still struggling in this respect or are in a state of evolution, ${ }^{18}$ thus our findings are likely to be applicable to a large proportion of the UK population.

\section{Comparison with other research}

Our finding of difficulty in obtaining testing replicates those of earlier reports. ${ }^{6}$ GPs citing the lack of appropriate specialist services as a way of managing requests for testing has also been previously identified as an issue in a national survey of UK GPs. ${ }^{9}$ Our in-depth interview study complements and builds on the findings from these quantitative studies. Clinician and patient/ parent attitudes to the uncertainty surrounding food allergy have been examined by $\mathrm{Hu}$ and colleagues, who found differing attitudes: ranging from the rationalistic (where decisions are based on scientific reasoning and probability) to the moralistic (where principles such as risk minimisation and protection predominate $)^{1920}$ and that conflicting attitudes led to dissatisfaction. We found little expressed dissatisfaction regarding attitudes, at least in our interviewees with anaphylaxis, rather they reported deficiencies in professional knowledge and service provision.

Our interviews aimed to capture participants' narrative accounts in relation to testing. This approach seeks to understand the patient's story within a narrative structure which itself confers meaning and shapes future experiences. Frank ${ }^{17}$ described the restitution narrative, as used by the parents of children with anaphylaxis out of the blue, as the default story of illness, reiterating the power of medicine to heal. In contrast, the quest narrative is characterised by the triumph of the individual over adversity. Its use by two participant groups-adults with anaphylaxis and the parents of children with delayed recognition of severe allergies - resulted in very different outcomes: the adults with anaphylaxis adapted to non-provision by relying (rightly or wrongly) on their own experience, while the parents, having ultimately obtained testing and recognition, saw the testing and professional expertise that they had won as vital tools for navigating the future. Our findings of a chaotic narrative structure in the adults without anaphylaxis is in keeping with other studies of adults with contested symptoms and conditions. ${ }^{21}$ These complex findings have parallels in other work exploring attitudes to anaphylaxis in adolescents and their parents. $^{22}$

In seeking to increase access, Levy et $a l^{23}$ considered whether primary care should develop a major role in allergy testing, as their earlier survey had suggested that obstacles may be relatively modest. 9 Our patient accounts, however, suggest that patients with severe allergy most valued the opinion of an expert in interpreting the tests. Simply making tests available to generalists without the expertise to interpret them would it seems not be appropriate.

\section{Implications for policy, practice and future research}

Service reviews ${ }^{624}$ have highlighted deficiencies in allergy service provision, and, although anaphylaxis is relatively uncommon, its

\section{Main messages}

- Access to allergy testing remains problematic for many people, particularly in primary care. These deficiencies in service provision are incorporated into patient's narrative accounts and influence the way they currently view their allergy and treatment.

- Patients and parents of children with allergy regard specialist interpretation of allergy testing as critically important. Expanding access to testing beyond specialist services - that is, without expertise in interpretation-is unlikely to meet patient needs and expectations.

- We found little interest in obtaining allergy testing from complementary and alternative medicine providers; rather, most patients wanted access to and advice from competent NHS providers. 


\section{Current research questions}

- How can primary care professionals be helped to recognise and refer children with high-risk allergic disorders at an early stage?

- Given the ongoing shortage of specialists in clinical allergy and our finding of the central importance of interpretive expertise, what service models (for instance, managed clinical networks) would maximise their effectiveness to patients?

- How can general practitioners deal effectively with patients who believe allergy to play a disproportionate role in their symptoms?

incidence is rising. ${ }^{2}{ }^{3}$ Recent expert guidelines suggest that allergen testing should be mandatory for cases of anaphylaxis, ${ }^{4}$ and it is clear from our data that testing needs to be part of an expert package of care for patients with, or at high risk of, anaphylaxis. The role of allergen testing in other allergic disorders is less clear. However, with the introduction of immunomodulatory disease-modifying treatments such as sublingual immunotherapy for grass pollen allergy ${ }^{25}$ and a possible role for oral desensitisation for peanut allergy ${ }^{26} 27$ and other conditions, ${ }^{28}$ the requirements for allergen testing are likely to increase within the foreseeable future. Developing a coherent allergy testing policy is therefore important, particularly with the ever increasing availability of alternative allergy tests of questionable scientific value.

\section{CONCLUSIONS}

We found, overall, major shortcomings in NHS allergy diagnostic provision. Some services received by children were considered appropriate and appreciated by their parents; however, the management of adults appeared to fall short of recommendations in current expert guidelines. Patients with severe allergy tended to have balanced views about allergy testing, which acknowledged the uncertainty implicit in testing but stressed the importance of expert interpretation of tests. In contrast, a number of patients unlikely to have severe allergy expressed a particularly strong desire for testing, either conventional or alternative, and believed that this should be provided by the NHS. Any strategic initiatives aiming to increase access to allergy testing need to be accompanied by a corresponding broadening in access to specialist interpretive ability.

Acknowledgements We thank the staff of participating practices, the allergy clinic at the Royal Hospital for Sick Children, Edinburgh and the Anaphylaxis Campaign and Andrea Kane and Alison Tate who transcribed the interviews.

Funding Chief Scientist Office of Scottish Government Health Directorate, St Andrews House, Edinburgh

Competing interests AS contributed to the Royal College of Physicians, Department of Health's and the Scottish Medical and Scientific Advisory Committee's reviews of allergy care. He also gave evidence to the House of Lords Allergy Inquiry. He is currently a member of the team reviewing progress with implementing the House of Lords' recommendations on allergy provision.

Patient consent Obtained
Ethics approval This study was conducted with the approval of the Lothian Research Ethics Committee.

Contributors The study was planned and supervised by $A S$ and $C B$ and conducted by $\mathrm{TI}$. TI and CB carried out the initial analysis, and CB drafted the paper. All contributors were involved in revisions to the paper. $A S$ and $C B$ act as guarantors.

Provenance and peer review Not commissioned; externally peer reviewed.

\section{REFERENCES}

1. Sheikh A, Alves B. Hospital admissions for acute anaphylaxis: time trend study. BMJ 2000:320:1441.

2. Simpson CR, Newton J, Hippisley-Cox J. Incidence and prevalence of multiple allergic disorders recorded in a national primary care database. $J R$ Soc Med 2008; 101:558-63.

3. Gupta R, Sheikh A, Strachan DP, et al. Time trends in allergic disorders in the UK. Thorax 2007:62:91-6.

4. Soar J, Pumphrey R, Cant A, et al. Emergency treatment of anaphylactic reactions-guidelines for healthcare providers. Resuscitation 2008;77:157-69.

5. Lieberman P, Kemp SF, Oppenheimer J, et al. The diagnosis and management of anaphylaxis: An updated practice parameter. J Allergy Clin Immunol 2005;115: S483-523.

6. House of Commons Select Committee. The provision of allergy services. London: The Stationery Office, 2004.

7. Royal College of Physicians. Allergy: the unmet need. A blueprint for better patient care. Sudbury, Suffolk: The Ladenham Press Ltd, 2003.

8. Brown AF, McKinnon D, Chu K. Emergency department anaphylaxis: a review of 142 patients in a single year. J Allergy Clin Immunol 2001;108:861-6.

9. Levy ML, Price D, Zheng X, et al. Inadequacies in UK primary care allergy services: national survey of current provisions and perceptions of need. Clin Exp Allergy 2004; 34:518-9.

10. Allergy UK. Pharmacy allergy screening service. http://www.allergyuk.org/ info_pharmacyfaq.aspx (accessed Jul 2009).

11. Scadding, Glenis K. Pharmacy allergy testing and diagnosis- the BSACl view. http:// www.bsaci.org/index.php?option $=$ com_content\&task $=$ viewধid $=148$ \&ltemid $=111$ (accessed Jun 2008).

12. Mullins RJ, Heddle RJ, Smith P. Non-conventional approaches to allergy testing: reconciling patient autonomy with medical practitioners' concerns. Med J Aust 2005:183:173-4

13. York Laboratories. http://www.yorktest.com/ (accessed Jul 2009).

14. Lewith GT, Kenyon JN, Broomfield J, et al. Is electrodermal testing as effective as skin prick tests for diagnosing allergies? A double blind, randomised block design study. BMJ 2001;322:131-4.

15. Gallagher M, Worth A, Sheikh A. Clinical allergy has much to gain from engagement with qualitative research. Allergy 2009;64:1117-19.

16. Corbin J, Strauss A. Grounded theory research, procedures, canons and evaluative criteria. Qual Sociol 1990;13:3-22.

17. Frank AW. The Wounded storyteller: body, illness and ethics. Chicago: Chicago University Press, 1995

18. Wardlaw A. Allergy services in the UK. J Clin Pathol 2006;59:892.

19. Hu W, Loblay R, Ziegler J, et al. Attributes and views of families with food allergic children recruited from allergy clinics and from a consumer organization. Pediatr Allergy Immunol 2008;19:264-9.

20. Hu W, Grbich C, Kemp A. When doctors disagree: a qualitative study of doctors' and parents' views on the risks of childhood food allergy. Health Expect 2008;11:208-19.

21. Nettleton S. 'I just want permission to be ill': towards a sociology of medically unexplained symptoms. Soc Sci Med 2006;62:1167-78.

22. Akeson N, Worth A, Sheikh A. The psychosocial impact of anaphylaxis on young people and their parents. Clin Exp Allergy 2007;37:1213-20.

23. Levy ML, Sheikh A, Walker $S$, et al. Should UK allergy services focus on primary care? BMJ 2006;332:1347-8

24. Scottish Medical and Scientific Advisory Committee. Review of allergy services in Scotland. Edinburgh: Scottish Government, 2008.

25. Durham SR, Yang WH, Pedersen MR, et al. Sublingual immunotherapy with oncedaily grass allergen tablets: a randomized controlled trial in seasonal allergic rhinoconjunctivitis. J Allergy Clin Immunol 2006;117:802-9.

26. Clark AT, Islam S, King Y, et al. Successful oral tolerance induction in severe peanut allergy. Allergy 2009;64:1218-20.

27. Hofmann AM, Scurlock AM, Jones SM, et al. Safety of a peanut oral immunotherapy protocol in children with peanut allergy. J Allergy Clin Immunol 2009;124:286-91, 291

28. Burks AW, Laubach S, Jones SM. Oral tolerance, food allergy, and immunotherapy: implications for future treatment. J Allergy Clin Immunol 2008;121:1344-50. 